\title{
O cidadão como produtor de informação: estudo de caso na imprensa online portuguesa
}

\author{
JoÃo CaNaVilHaS \\ Universidade da Beira Interior (UBI) - Portugal - jc@ubi.pt \\ Licenciado em Comunicação Social (UBI), DEA em Comunicación Audiovisual y Publicidad e Doutor pela \\ Universidad de Salamanca
}

CATARINA Rodrigues

Universidade da Beira Interior (UBI) - Portugal - catsofia@ubi.pt Pesquisadora junto ao Laboratório de Comunicação OnLine (Labcom-UBI)

\begin{abstract}
Resumo
Classificado por alguns autores (Gilmor, 2005; Rosen, 2008) como um dos grandes desafios ao jornalismo tradicional, o chamado "jornalismo do cidadão" está longe de cumprir as promessas iniciais. Independentemente da sua localização e dimensão, muitos dos mais promissores projetos exclusivamente dinamizados por cidadãos ou criados com essa finalidade nos media online perderam o fulgor inicial ou encerraram. Em Portugal, as versões online dos maiores diários também criaram secções para a participação dos cidadãos, alguns dos quais utilizam as palavras "jornalismo" ou "repórter" na sua denominação. Mas poderemos chamar "jornalismo" aos textos publicados nestes espaços? Para responder a estas e outras questões, foi efetuada uma análise de conteúdo aos textos publicados pelos leitores em seç̧ões específicas existentes em quatro diários portugueses. O objetivo principal é verificar se existem elementos característicos da prática jornalística, ou seja, se os cidadãos fazem jornalismo nos espaços denominados "jornalismo cidadão".
\end{abstract}

\section{Palavras-chave}

participação, cidadãos, fontes, jornalismo online.

\begin{abstract}
Considered by some authors (Gilmor, 2005; Rosen, 2008) as one of the traditional journalism greatest challenges, the so called "citizen journalism" is far from delivering its original promises. Regardless of their location and dimension, some of the most promising online media projects developed by citizens or created with this aim, lost their initial effulgence or closed down completely. In Portugal, the online versions of the major daily newspapers also created sections for citizens participation, some of them using the word "journalism" or "reporter" in their denomination. But can we consider "journalism" the texts published on these spaces? To answer this and other questions, an analysis of contents published by readers in the specific sections of four Portuguese daily newspapers was carried out. The main aim is to verify if there are characteristic elements in journalistic practice, i.e. if citizens do journalism in the spaces denominated as "citizen's journalism"
\end{abstract}

Keywords

participation, citizens, sources, online journalism. 


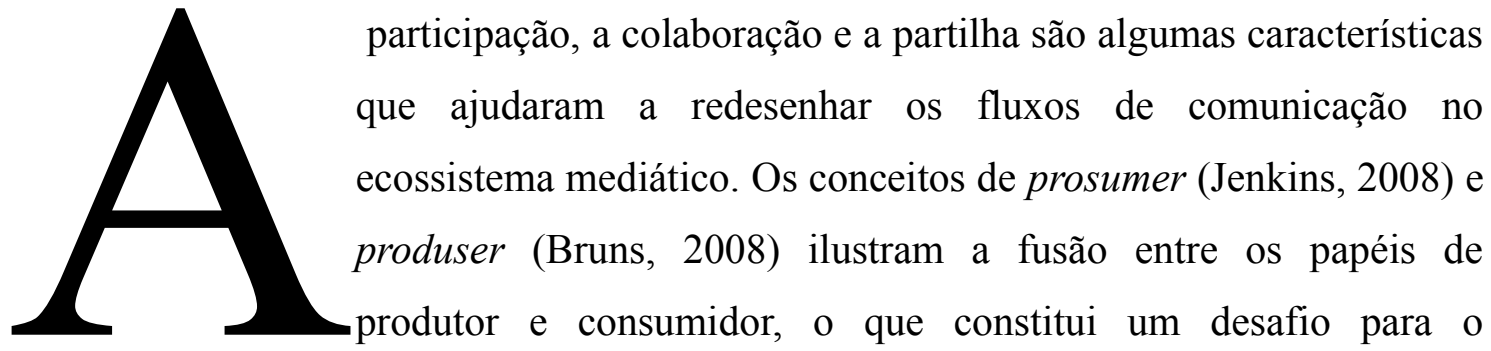
jornalismo e para as relações que se estabelecem entre jornalistas e leitores (Heinonen, 2011; Domingo, 2008 e 2011; Chung, 2008). A entrada dos leitores no campo jornalístico colocou os profissionais perante novos desafios devido à possibilidade das pessoas que, antes conhecidas como audiência (Rosen, 2006), passaram a ter acesso a fontes de informação, a formas de distribuição de conteúdos e a espaços destinados a publicação, não apenas em blogues com visibilidade restrita, mas a publicações exclusivamente dedicadas a cidadãos ou mesmo a espaços criados pelos jornais online para este fim.

Considerando sobretudo o último ponto, este trabalho procura analisar os conteúdos publicados pelos cidadãos nos espaços criados pelos jornais online portugueses para esta finalidade. Interessa-nos saber quais as temáticas predominantes, que tipos de fontes estão na base dos conteúdos publicados e, mais importante do que isso, perceber se os textos publicados pelos cidadãos podem ser considerados jornalismo. Para esta análise serão ponderadas as especificidades da informação noticiosa, bem como as práticas e regras que norteiam a profissão.

\section{Jornalismo e cidadãos}

Os meios de comunicação têm procurado incentivar a participação dos cidadãos através de diferentes práticas, potencializando a natureza colaborativa da Web. Comentar notícias, participar em fóruns, responder a inquéritos, atualizar blogues, contribuir para a realização de entrevistas coletivas, partilhar conteúdos nas redes sociais, enviar fotos, vídeos e textos para publicação no próprio espaço do jornal, são algumas das formas de participação que os leitores encontram em grande parte dos media online. Esta diversidade de possibilidades deu origem a uma vasta nomenclatura que procura caracterizar as experiências que foram surgindo: "jornalismo cidadão" (Gillmor, 2005; Meso, 2005; Rosen, 2008), “jornalismo colaborativo" (Glaser, 2004), “jornalismo 3.0" (Varela, 2005) e "jornalismo participativo" (Bowman e Willis, 2003; 
Thurman e Hermida, 2010; Singer et al, 2011) são alguns exemplos de nomes que procuram integrar a participação dos cidadãos no ecossistema mediático, ou seja, o "acto de um cidadão ou grupo de cidadãos que têm um papel ativo no processo de recolha, análise, produção e distribuição de notícias e informações" (Bowman e Willis 2003:9). Para Rosen (2008), "quando as pessoas anteriormente conhecidas como audiência utilizam as ferramentas de publicação que têm ao seu dispor para se informarem umas às outras isso é jornalismo do cidadão". Esta simplificação, assente na ideia de qualquer cidadão publicar e difundir informação, desempenhando assim um papel ativo na produção de conteúdos, acaba por ser um elemento comum aos conceitos acima referidos. Singer et al acrescentam ainda que o jornalismo participativo "capta a ideia de colaboração e ação coletiva - não apenas paralela. As pessoas dentro e fora da redação estão envolvidas na comunicação, não só para, mas também com os outros" (2011, p.2).

Diferentes momentos da história recente mostraram a motivação dos utilizadores em divulgar informações sobre determinados acontecimentos: o 11 de Setembro de 2001, a Guerra no Iraque, o furacão Katrina, os confrontos no Irão ou a recente Primavera Árabe são exemplos disso mesmo. Apesar do inegável interesse da informação distribuída por cidadãos envolvidos nestes acontecimentos, o seu efeito depende da forma como é elaborada e, sobretudo, da forma como é distribuída, isto é, do espaço onde é tornada pública. A este propósito, Thurman e Hermida (2010) chamam a atenção para a necessidade de distinguir projetos independentes de jornalismo cidadão das formas proporcionadas pelos media para a participação. A nossa pesquisa centra-se precisamente na participação concretizada no espaço disponibilizado pelos meios de comunicação.

\section{Elementos do jornalismo}

As denominações "Cidadão Repórter" (JN) e "Jornalismo de Cidadão" (DN) parecem indiciar a existência de informação de cariz noticioso nestes espaços, o que levanta algumas questões relacionadas com as características da prática jornalística.

Na obra The Elements of Journalism: What Newspeople Should Know and The Public Should Expect, Kovach e Rosenstiel (2004) traçam as ideias fundamentais para que o jornalismo assegure o seu lugar de destaque na sociedade, como vigilante do Governo ou das instituições e como garantia da vida democrática. Procura da verdade, 
lealdade para com os cidadãos, disciplina de verificação, independência em relação àqueles sobre os quais informa, vigiar o poder de forma independente, espaço para a crítica e o compromisso público, tornar interessante e relevante aquilo que é significativo, garantir notícias abrangentes e proporcionadas, sendo que os jornalistas devem ser livres para trabalhar de acordo com sua própria consciência, são os princípios enunciados pelos autores. Numa nova edição do livro, publicada em 2007, Kovach e Rosenstiel acrescentaram um décimo elemento relacionado com os direitos $\mathrm{e}$ responsabilidades dos cidadãos no que diz respeito à informação noticiosa.

O exercício da profissão obedece assim a rotinas e procedimentos que, de uma forma simplificada, são a seleção e interpretação de dados, a contextualização dos factos, a identificação dos atores intervenientes nos acontecimentos, a verificação dos dados e o contraste de fontes.

\section{Fontes e diversidade}

Com o advento da Internet, o acesso às fontes e a recolha de informação sofreram transformações significativas. As ferramentas da Web 2.0, como os blogues, os microblogues e as redes sociais, contribuíram para um aumento da velocidade nestas duas fases do processo de produção noticiosa, mas criaram igualmente novos desafios, nomeadamente em relação à exigência e rigor na verificação dos factos.

As fontes são um elemento fundamental no jornalismo e são essenciais para assegurar a credibilidade da informação. Existem diferentes tipologias de fontes que Pinto (2000) classifica segundo a natureza, a origem, a duração, o âmbito geográfico, o grau de envolvimento nos factos, a atitude face ao jornalista, a identificação, a estratégia de atuação. Crato (1992) divide as fontes em internas e externas, colocando no primeiro grupo os jornalistas (investigação e observação direta), os correspondentes e o arquivo, classificando como fontes externas as agências noticiosas, os outros órgãos de comunicação social, as entidades oficiais (Governo, Assembleia da República, ministérios, câmaras municipais, forças policiais, etc.), as entidades não oficiais (empresas, coletividades, sindicatos, associações culturais, clubes desportivos, etc.), os contactos pessoais e o público.

Independentemente da classificação adotada, parece claro existir uma enorme variedade de fontes e daí a necessidade de organizá-las de acordo com a sua tipologia. Este facto está na origem da diversidade de notícias publicadas pelos jornais, que 
habitualmente são organizadas em editorias para guiar o leitor: a ser assim, uma das marcas diferenciadoras de uma publicação jornalística é a variedade de temas, algo a que Groth chama universalidade (Fidalgo, 2004) e que deve incluir não só notícias relativas ao mundo físico, como ainda à sociedade e à cultura. Por isso mesmo, uma das hipóteses deste trabalho é que os textos publicados pelos cidadãos nos jornais online são pouco diversificados e, a ser assim, pouco universais, o que os afasta da atividade jornalística.

\section{Fontes e produção de informação}

Algumas investigações (Hermida e Thurman, 2008; Domingo et al, 2008) têm demonstrado que os meios de comunicação continuam a preservar o papel de gatekeeping e controlam a participação. As possibilidades participativas disponibilizadas pelos meios de comunicação são várias, contudo isso não significa que exista de facto um envolvimento entre jornalistas e leitores, até porque em muitos casos a participação cidadã funciona em canais separados e bem delimitados dos conteúdos profissionais. David Domingo (2011) analisa a forma como as contribuições dos utilizadores são recebidas, filtradas e publicadas e distingue duas categorias principais no que se refere às estratégias participativas seguidas pelas redações online: jornalismo participativo como playground e jornalismo participativo como fonte. Com a ideia de playground, Domingo refere-se a espaços vagamente moderados que, por estarem concentrados numa secção específica para o efeito, protegem a marca do jornal de possíveis interferências causadas por conteúdos gerados pelos utilizadores. Hermida (2011) nota alguma resistência dos meios em deixar a audiência (normalmente vista como fonte) participar na agenda e na produção do jornal. Embora seja notória uma maior abertura ao diálogo com os utilizadores, "os jornalistas ainda se veem como os atores que definem o processo de criação de notícias" (Heinonen, 2011).

Neste sentido, talvez seja interessante observar a experiência que está a ser desenvolvida pelo britânico The Guardian que, desde outubro de 2011, tem tornado públicos alguns temas da agenda do jornal, a "open newslist", solicitando a contribuição dos leitores para a elaboração de notícias. López García salienta que existem diferentes níveis de intervenção na produção noticiosa ao nível da participação dos cidadãos no espaço dos meios de comunicação. "A gestão de todos eles deve recair sempre na figura do jornalista que, como mediador profissional e intérprete do que acontece, tem que 
zelar pelo objetivo prioritário da informação: que seja verídica e esteja ao serviço da sociedade" (2009, p. 145). Também Moretzsohn sublinha que existe especificidade na mediação jornalística e por isso jornalista "é aquele profissional autorizado a estar onde o público não pode estar, e por isso tem direito ao acesso a fontes através das quais pode apurar as informações necessárias à sociedade" (2006, p. 68).

Um estudo realizado por Zvi Reich (2008) comparou jornalistas profissionais e cidadãos nas práticas de produção de notícias. O autor partiu da hipótese que os cidadãos estão em desvantagem nessa tarefa porque têm mais dificuldades no acesso às fontes de informação. Este problema pode, segundo Reich, ser minimizado através do recurso a outros mecanismos como a pesquisa de histórias por iniciativa própria. $\mathrm{O}$ autor considera que existem algumas características que limitam o trabalho dos cidadãos-repórteres: estão normalmente fora das rotinas e fontes, como conferências de imprensa e press releases; estão normalmente dependentes de outros cidadãos comuns e não dos círculos mainstream constituídos por fontes institucionais e profissionais de relações públicas; têm poucas possibilidades de cultivar relações com as fontes; têm um conhecimento jornalístico limitado; e normalmente têm outras atividades profissionais (Reich, 2008, pp. 741-742). Esta dificuldade no acesso a alguns tipos de fontes, bem como o facto de não desenvolverem o jornalismo como profissão, poderá justificar outra das hipóteses deste trabalho: nos textos produzidos pelos cidadãos não existe o contraste e variedade de fontes característicos dos textos jornalísticos.

Para além da forma como são utilizadas as fontes, o reconhecimento da prática jornalística também pode ser efetuada com a identificação de um conjunto de características que, segundo Otto Groth, (Fidalgo, 2004) definem o que é um jornal: periodicidade (publicação em espaços regulares), universalidade (informação sobre tudo o que diga respeito ao Homem a à sua ação social e cultural), atualidade (algo que acontece no tempo presente e é novo) e a publicidade (acessibilidade do jornal a todos).

A utilização simultânea de alguns dos princípios enunciados por Kovach e Rosenstiel (2004) e das características que, segundo Groth, definem o que é um jornal, funcionarão como grelha de análise para identificar se os textos publicados pelos cidadãos nos jornais online portugueses podem ser considerados jornalismo.

\section{Estudos anteriores}

Num estudo exploratório sobre o papel do público no jornalismo participativo, 
Saad e Madureira concluíram que "o cidadão repórter brasileiro que atua nos grandes portais não tem comprometimento nem estímulo para apurar informações e realizar cruzamento de fontes, práticas comuns e necessárias à disciplina de verificação de dados" (2010, p. 176). Nas publicações observadas em Portugal os resultados são similares. Saad e Madureira também constataram que, no Brasil, a participação dos utilizadores não é sinónimo de um maior envolvimento dos leitores com a produção de informação. Ao observarem que os textos utilizavam as próprias declarações do colaborador entre aspas, os autores referem que "nos grandes portais brasileiros o cidadão repórter é meramente um cidadão fonte" (Saad e Madureira, 2010, p. 177), alguém que participa de forma ativa nos espaços que lhe são disponibilizados, mas que está sujeito ao filtro dos profissionais.

Também o estudo desenvolvido por Zamith (2012) conclui que nos textos publicados pelos cidadãos nos jornais online não existem sinais de confirmação da informação, da observância do princípio do contraditório ou da necessária independência em relação aos temas tratados. O autor sublinha que os cidadãos se limitam a publicar a sua versão dos acontecimentos, "nem que para isso tenha de omitir informações ou até deturpar factos" (Zamith, 2012, p. 329).

Considerando, por um lado, que o "o processo de recolha de informação ficou mais abrangente, mais rico e superiormente vasto para a produção noticiosa" (Gomes, 2009, p.106) e, por outro lado, que parecem estar criadas condições para que os cidadãos possam ter uma participação ativa nos jornais online, neste trabalho procuramos identificar a existência de alguns elementos distintivos da prática jornalística nos textos publicados pelos cidadãos nestes espaços criados pelos jornais online para essa finalidade.

\section{Metodologia}

A metodologia de investigação utilizada nesta pesquisa é a análise de conteúdo aos textos publicados pelos cidadãos nas secções dedicadas à sua participação nos jornais online portugueses. A análise de conteúdo é "uma técnica de investigação que procura uma descrição objetiva, sistemática e quantitativa do conteúdo manifesto da comunicação" (Berelson, 1952, p. 18). Para Bardin, esta técnica procura obter "por procedimentos sistemáticos e objetivos de descrição do conteúdo das mensagens, indicadores (quantitativos ou não) que permitam a inferência de conhecimentos 
relativos às condições de produção/recepção destas mensagens” (1979, p.42). Já Igartua e Humanes consideram que se trata de "uma técnica de investigação que permite descobrir o «ADN das mensagens mediáticas», dado que a referida análise permite reconstruir a sua arquitetura, conhecer a sua estrutura, os seus componentes básicos e o funcionamento dos mesmos" (2010, p. 75).

Foram selecionados para o estudo jornais online generalistas portugueses de âmbito nacional que têm um espaço onde os cidadãos podem publicar textos. Assim, serão analisadas as seguintes secções: "Correio do Leitor" do Correio da Manhã (CM); “Jornalismo de Cidadão" do Diário de Notícias (DN); "Cidadão Repórter" do Jornal de Noticias (JN); e "iRepórter" do jornal $I$.

O objetivo deste trabalho não passa por comparar as publicações entre si, mas sim observar as características de cada secção e dos conteúdos aí publicados procurando características definidas na parte teórica como sendo indiciadoras da existência de um texto de cariz jornalístico.

Antes de mais, convém referir a heterogeneidade dos espaços analisados, desde logo pelas especificidades próprias de cada publicação. O "Correio do Leitor" é uma secção do Correio da Manhã destinada à intervenção dos utilizadores. "Vamos dar uma voz ativa às suas queixas, reclamações e notícias" é a mensagem que pode ler-se no site. Neste caso, os conteúdos dos leitores são distribuídos por espaços como "A foto do leitor e a sua legenda" ou "Caixa de reclamações". Nesta última, os leitores podem fazer as suas queixas (normalmente relacionadas com problemas locais ou instituições públicas) que são depois encaminhadas pela equipa do jornal para as entidades competentes: a resposta é publicada juntamente com os conteúdos enviados pelo leitor. O "Correio do Leitor" faz parte da secção "Outros" com link no cabeçalho da página inicial. Os conteúdos podem ser enviados por e-mail e por correio tradicional. O Correio da Manhã não publica regras ou normas que devam ser seguidas pelos leitores, deixando apenas algumas sugestões sobre temas que podem ser publicados.

O "Jornalismo de Cidadão", do Diário de Notícias, incentiva a publicação de artigos, fotos e vídeos dos seus leitores. Os conteúdos podem ser enviados para um endereço de e-mail disponibilizado para o efeito. Tem uma chamada no final da página do jornal e está incluído na secção "Opinião".

O "Cidadão Repórter", que integra o Jornal de Notícias, está em destaque no cabeçalho do jornal, junto das restantes secções. Solicita o envio de notícias e 
fotografias aos leitores através de um endereço de e-mail. Em ocasiões específicas, o próprio jornal incentiva a colaboração dos leitores.

O "iRepórter" era uma secção do jornal I (o último texto foi publicada a 14 de Setembro de 2011 e posteriormente foi suspensa) que convidava os leitores a enviar conteúdos (artigos, fotografias e vídeos) através de um registro com os seguintes elementos: e-mail, password, nome, apelido, data de nascimento (obrigatórios), sexo profissão, sector de atividade. O utilizador podia acrescentar outros dados como a sua fotografia, o seu blogue e respetivo endereço, etc. Para os conteúdos serem publicados era necessário cumprir algumas regras enunciadas no site, nomeadamente em relação ao formato das fotografias. Nenhuma das restantes publicações analisadas disponibiliza regras ou normas que devam ser seguidas pelos leitores que enviem conteúdos e todos permitem comentários.

Com exceção do Correio da Manhã, foram analisados todos os textos publicados diariamente nos referidos espaços nos meses de abril, maio e junho de 2010 . No caso do $\mathrm{CM}$, dado o elevado número de conteúdos publicados, e tendo por base os argumentos de Bauer (2000) e Herscovitz (2007), procedemos à construção de semanas artificiais: em abril começámos por selecionar a primeira segunda-feira do mês, na semana seguinte a terça-feira e assim sucessivamente. No caso específico desta publicação foi analisada uma semana por mês. Esta estratégia permitiu-nos obter uma amostra variada com uma distribuição equitativa, garantindo a representatividade do universo de estudo. No período estipulado, e na totalidade das publicações, foram recolhidos e analisados 139 textos.

Com o objetivo de identificar as principais temáticas abordadas pelos cidadãos no espaço dos jornais, foram estabelecidas as seguintes categorias: Política (textos referentes a instituições governativas nacionais e locais, governantes, partidos políticos, atores políticos, decisões políticas, etc.); Sociedade (textos relacionados com a vida dos cidadãos, nomeadamente o emprego, o desemprego, os transportes, a segurança, a religião, o urbanismo e o ambiente); Economia (textos referentes aos mercados financeiros, às taxas de juro, aos bancos, aos impostos, à bolsa de valores, ao orçamento do Estado, à inflação e ao preço dos mais variados produtos); Desporto (textos relacionados com a prática desportiva das diferentes modalidades); Saúde (textos relacionados com instituições de saúde, doenças, medicamentos e ações de rastreio); Tecnologia (textos relacionados com produtos informáticos, industriais e gadgets); Educação e Ciência (textos referentes a todos graus de ensino, incluindo a investigação 
realizada nos ensino superior, greves de professores e manifestações de estudantes); Justiça (textos referentes a tribunais ou relacionados com questões de âmbito judicial); Cultura (textos referentes a cinema, teatro, música, moda, pintura ou qualquer outra forma de expressão artística, espetáculos, festivais, associações culturais e tradições locais); e Outro (textos que, por algum motivo, não se enquadram nas categorias anteriores).

No que concerne às fontes foram consideradas as tipologias de fontes defendidas por Ericson et al (1991) e também por Crato (1992), tendo sido feitas as adaptações necessárias ao objeto de estudo. Assim, incluímos os seguintes parâmetros relativamente às fontes usadas: "testemunho próprio", "fontes oficiais" (instituições governamentais e sector público), “fontes não oficiais” (empresas privadas, coletividades, etc.), "media" (com o objetivo de quantificar o número de vezes em que os textos da autoria dos cidadãos se baseiam noutros trabalhos já difundidos nos meios de comunicação) e, por fim, "outras" (por constatarmos que, em muitos casos, não era possível identificar as fontes). Para além do tipo de fontes usadas, foi ainda observada a existência ou não de contraste das mesmas e de citações nos textos.

\section{Análise e discussão de resultados}

Dos 139 textos analisados, 92 foram publicados na secção "Correio do Leitor" do Correio da Manhã, 26 no "Cidadão Repórter" do Jornal de Notícias, 11 no "Jornalismo de Cidadão" do Diário de Notícias, e 10 no "iRepórter" do jornal I. Se pensarmos que os números referentes ao $I$, $\mathrm{DN}$ e $\mathrm{JN}$, se referem à totalidade de conteúdos publicados num espaço temporal de três meses, podemos desde logo constatar que participação dos cidadãos nestes espaços é reduzida. Esta constatação permite concluir que não existe uma periodicidade no sentido definido por Groth (Fidalgo, 2004), o que revela um primeiro afastamento destes espaços em relação ao jornalismo.

Em 49 (53\%) dos 92 textos publicados no CM, o autor não aparece identificado. O mesmo acontece em seis (23\%) textos do JN. Ainda assim, neste último caso, é feita a referência "Leitor identificado" pelo jornal. A identificação do autor é um elemento importante para a responsabilização sobre os conteúdos publicados. Apenas no jornal $I$ é possível entrar em contacto com o autor através do endereço de e-mail disponibilizado juntamente com o texto. De um modo geral, há uma predominância de autores do sexo 
masculino: $70 \%$ no $\mathrm{CM}, 82 \%$ no $\mathrm{DN}, 75 \%$ no $\mathrm{JN}$, e $100 \%$ no $I$.

Sociedade é o tema predominante no Jornal de Notícias (88\%) e no Correio da Manhã (55\%). No Jornal de Notícias apenas são focadas outras duas temáticas: Desporto (8\%) e Educação e Ciência (4\%). No Correio da Manhã segue-se Cultura (25\%) Educação e Ciência (10\%), Desporto (7\%), Saúde (2\%) e por fim, Política (1\%). No Diário de Notícias, $73 \%$ dos textos são sobre Política, tendo ainda sido publicados conteúdos sobre Sociedade, Economia e Cultura (9\% cada). No I, 40\% dos textos são sobre Cultura, seguindo-se Sociedade (20\%) e Economia (20\%), e por fim Educação e Ciência (10\%) e Outro (10\%). Face aos dados obtidos, constata-se a predominância de temáticas sobre Sociedade (56\% do total) e de assuntos relacionados com vivências quotidianas que acabam por se refletir nas intervenções dos autores. A variedade de temas, que Groth define como universalidade e Kovach e Rosenstiel como notícias abrangentes, não se verifica, havendo uma clara preponderância de textos relacionados com o dia-a-dia dos cidadãos, o que afasta estes espaços dos jornais, que vulgarmente registam um relativo equilíbrio nas três ou quatro temáticas mais importantes.

No Correio da Manhã, 33\% do conteúdo publicado baseia-se no "testemunho próprio" e em $52 \%$ dos textos não foi possível identificar as fontes. Este número devese à predominância de informações publicadas sem identificação do respetivo autor ou sem qualquer referência no texto à fonte de informação. Nos textos publicados pelos cidadãos neste jornal, são utilizadas fontes oficiais em $13 \%$ dos casos e fontes não oficiais em $2 \%$. No total, dos 139 textos observados, apenas 8 contrastaram fontes de informação. Este número surge associado à "Caixa de Reclamações" do Correio da Manhã, espaço onde entidades oficiais respondem a problemas colocados pelos leitores, sendo que, importa referir neste ponto a mediação jornalística que existe entre os diferentes atores. No Jornal de Notícias, a percentagem de textos baseados em "testemunho próprio" é de 84\%, seguem-se as fontes não oficiais (8\%), os media e “outras" (4\% cada). No Diário de Notícias, 55\% dos textos baseiam-se em "testemunho próprio", $36 \%$ nos media e $9 \%$ em fontes oficiais. No I, 90\% dos textos baseiam-se em "testemunho próprio" e 10\% em fontes não oficiais. Em termos globais constatamos que $48 \%$ dos textos baseiam-se no testemunho próprio do autor e em $35 \%$ não é possível identificar a fonte. Apenas $9 \%$ dos autores citam fontes oficiais. A percentagem de fontes não oficiais e de textos baseados em conteúdos já difundidos nos media é de 4\% cada.

Em 133 textos não é feita qualquer citação, algo que apenas acontece em seis 
textos (2 do Diário de Notícias, 2 do Jornal de Notícias, 1 do Correio da Manhã e 1 do I). No total, $77 \%$ dos conteúdos apresentam uma única fonte, o próprio autor, $18 \%$ apresentam duas fontes de informação e apenas 5\% apresenta três ou mais fontes.

Estes dados remetem para questões relacionadas com a fiabilidade das informações transmitidas. Os resultados indicam que a maioria dos autores não tem presentes elementos básicos do jornalismo, como o princípio do contraditório, o que vai ao encontro de estudos já realizados noutros países (Carpenter, 2008; Saad e Madureira, 2010; Domingo, 2011; Zamith, 2012). A procura da verdade, a disciplina de verificação dos factos, a independência e a variedade de fontes, princípios enunciados por Kovach e Rosenstiel, são completamente ignorados, sendo este facto o que mais afasta estes textos da atividade jornalística.

\section{Conclusão}

A internet redefiniu a relação entre jornalistas, fontes e público, bem como as funções desempenhadas por cada um no ecossistema mediático. As fontes, que dependiam dos jornalistas, passaram a ter acesso direto aos canais de distribuição de informação. O público, que era apenas o consumidor final, tem agora acesso a algumas fontes e ao espaço público, graças aos blogues e redes sociais. Os jornalistas, que serviam de intermediário entre os dois atores anteriores, perderam a exclusividade no acesso ao espaço público, e assistiram ao nascimento daquilo a que alguns chamam "jornalismo do cidadão". Mas poderemos chamar "jornalismo" aos textos publicados pelos cidadãos nos espaços criados pelos jornais online para esse efeito?

A análise aos conteúdos publicados nos espaços do cidadão criados nos jornais online portugueses confirmam os resultados obtidos em pesquisas anteriores (Carpenter, 2008; Saad e Madureira, 2010; Domingo, 2011; Zamith, 2012): os conteúdos dos cidadãos não são jornalismo.

Desde logo, porque na maioria dos casos não existe qualquer periodicidade, contrariando um das condições enunciadas por Groth (Fidalgo, 2004). Nos meios estudados, o Correio da Manhã é o jornal que regista um maior número de atualizações, mas a maioria dos textos resume-se a um parágrafo, o que os afasta do conceito de notícia.

As temáticas abordadas nos textos dos cidadãos são pouco variadas, com $75 \%$ dos textos a pertencerem a apenas duas categorias. Também neste caso existe um 
afastamento em relação a uma das condições enunciadas por Groth - a universalidade situação eventualmente originada pelo facto de algumas fontes não fornecerem informações a não jornalistas.

As questões relacionadas com fontes revelam-se novamente na predominância de histórias vividas na primeira pessoa, com os textos a usarem unicamente o testemunho do próprio do autor ou a não identificarem as fontes usadas. Ao não contrastarem de fontes, não apresentarem diversidade de pontos de vista, de citações nos textos ou distinguirem claramente factos de opiniões, os cidadãos demonstram desconhecer alguns dos procedimentos básicos do jornalismo. Estes dados colocam em causa os elementos do jornalismo defendidos por Kovach e Rosenstiel (2004), nomeadamente no que diz respeito ao rigor, à disciplina de verificação, à confirmação dos fatos, à existência de fontes seguras e contrastadas, e no fundo a um conjunto de práticas fundamentais para fomentar a credibilidade da informação.

Por fim, uma análise gráfica à colocação dos espaços dedicados aos cidadãos permite observar uma clara delimitação entre os conteúdos produzidos por profissionais e por não profissionais, o que remete para o conceito de playground defendido por Domingo (2011). Em rigor, essas diferenças são claramente visíveis nos próprios conteúdos produzidos, como antes foi referido: chamar "jornalismo" ao que os leitores fazem nos espaços disponibilizados pelos jornais online portugueses só pode ser má-fé ou ignorância em relação aos procedimentos e regras básicas da atividade jornalística.

Este estudo constitui uma análise exploratória das experiências que têm vindo a ser concretizadas em Portugal no que diz respeito à participação dos cidadãos no espaço dos jornais. Numa investigação mais alargada a realizar no futuro, procuraremos analisar outros elementos como a visibilidade dos conteúdos dos cidadãos no site dos jornais, o controlo da participação, a existência ou não de elementos multimédia e as estratégias editoriais que têm vindo a ser seguidas pelos media.

\section{Bibliografia}

BARDIN, Laurence. Análise de Conteúdo. Lisboa: Edições 70, 2000, 225 p.

BAUER, Martin W. Classical Content Analysis: a Review. In Qualitative Researching with text, image and sound. A practical handbook. Londres: Sage. pp. 131-151.

BERELSON, Bernard. Content Analysis in Communication Research. New York: The Free Press, 1952, $220 \mathrm{p}$.

BOWMAN, Shayne; WILLIS, Chris. Nosotros, el médio - Cómo las audiencias están modelando el futuro de la noticias y la información. 2003. Disponível em:

<www.hypergene.net/wemedia/espanol.php $>$. Acesso em: 16 de jul. 2012. 
BRUNS, Axel. Blogs, Wikipedia, Second Life and Beyond: From Production to Produsage. New York: Peter Lang, 2008, 418 p.

CARPENTER, Serena. Source Diversity in U.S. Online Citizen Journalism and Online Newspaper Articles. In International Symposium on Online Journalism, 2008. Disponível em:

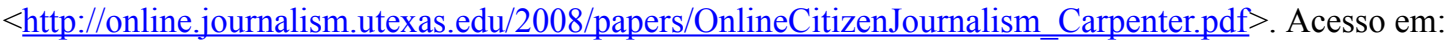
16 de jul. 2012

CRATO, Nuno. Comunicação Social. A Imprensa. Lisboa: Editorial Presença. 1992, 278 p.

DOMINGO, David et al. Participatory, journalism practices in the media and beyond: na international comparative study of iniciatives in online newspapers. In Journalism Practice, 2 (3), 2008, pp. 326-342. DOMINGO, David, Managing Audience Participation. Practices, workflows and strategies. In SINGER, Jane B. et al, Participatory Journalism: Guarding Open Gates at Online Newspapers, New York, Wiley-Blackwell, 2011, pp.76-95.

ERICSON, Richard V.; BARANEK, Patricia, M.; CHAN, Janet B. L. Representing Order: Crime, Law and Justice in the News Media. Buckingham: Open University, 1991, 383 p.

FIDALGO, António. Jornalismo Online segundo o modelo de Otto Groth. Disponível em $<$ http://www.bocc.ubi.pt/pag/fidalgo-groth-jornalismo-online.html\#htoc4>. Acesso em 02 de ago.2012

GILLMOR, Dan. Nós os Media. Lisboa: Editorial Presença, 2005.

GLASER, Mark. Collaborative Conundrum: Do Wikis Have a Place in the Newsroom? In Online Journalism Review, 2004. Disponível em:

$<$ http://www.ojr.org/ojr/glaser/1094678265.php>. Acesso em: 16 de jul. 2012.

GOMES, Rui Miguel. A importância da Internet para jornalistas e fontes. Lisboa: Livros Horizonte, 2009, 135 p.

HERMIDA, Alfred; THURMAN, Neil. A clash of cultures: The integration of user-generated contente within professional journalistic frameworks at British newspapers websites. In Journalism Practice, 2(3), 2008, pp. 343-356.

HEINONEN, Ari, “The Journalist's Relationship with Users. New dimensions to conventional roles". In SINGER, Jane B. et al, Participatory Journalism: Guarding Open Gates at Online Newspapers. New York: Wiley-Blackwell, 2011, pp. 34-55.

HERMIDA, Alfred, "Fluid Spaces, Fluid Journalism. The Role of the «active recipient» in participatory journalism”. In SINGER, Jane B. et al, Participatory Journalism: Guarding Open Gates at Online Newspapers, New York: Wiley-Blackwell, 2011, pp. 13-33.

HERSCOVITZ, Heloiza Golbspan. Análise de conteúdo em jornalismo. In LAGO, Cláudia; BENETTI, Marcia (Org.), Metodologia de pesquisa em jornalismo, Petrópolis: Editora Vozes, 2007, 286 p.

IGARTUA, Juan José; HUMANES, María Luisa. Teoría e investigación en Comunicación Social. Madrid: Editorial Sintesis, 2010, 462 p.

JENKINS, Henry. Convergence Culture. La Cultura de la Convergencia de los Medios de Comunicación. Barcelona: Paidós, 2008, 301 p.

KOVACH, Bill; ROSENSTIEL, Tom. Os Elementos do Jornalismo. O que os profissionais do jornalismo devem saber e o público deve exigir. Porto: Porto Editora, 2004, 234 p.

LÓPEZ GARCÍA, José. A participación cidadá no xornalismo: ¿reclamo ou diálogo? In Observatorio (OBS*), n. ${ }^{\circ}$ 8, 2009, pp. 138-147. Disponível em:

<http://www.obs.obercom.pt/index.php/obs/article/view/118 > . Acesso em: 16 de jul. 2012.

MESO, Koldo. Periodismo Ciudadano: voces paralelas a la profesión peridodística, In Chasqui, n. ${ }^{\circ} 90$, 2005, p.4-15.

MORETZSOHN, Sylvia. O mito libertário do «jornalismo cidadão», Comunicação e Sociedade Jornalismo e Internet, vol. 9-10, 2006, p. 63-81.

PINTO, Manuel. Fontes jornalísticas: contributos para o mapeamento do campo. In Comunicação e Sociedade 2, Cadernos do Noroeste, Série Comunicação, Vol. 14 (1-2), 2000, pp. 277-294.

REICH, Zvi. How citizens create news stories - The «news access» problem reversed. In Journalism Studies, Vol. 9, 5, 2008, pp. 739-758.

ROSEN, Jay, A Most Useful Definition of Citizen Journalism, 2008. Disponível em:

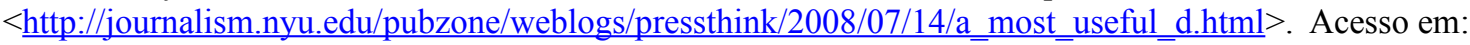
16 de jul. 2012. 
SAAD CORRÊA, Elizabeth; MADUREIRA, Francisco. Jornalista cidadão ou fonte de informação: estudo exploratório do papel do público no jornalismo participativo dos grandes portais brasileiros. In Estudos em Comunicação, 2010, nº 7 - Volume 1, pp. 157-184. Disponível em: $<$ http://www.ec.ubi.pt/ec/07/>. Acesso em: 16 de jul. 2012.

SINGER, Jane B. et al. Participatory Journalism: Guarding Open Gates at Online Newspapers. New York: Wiley-Blackwell, 2011, 227 p.

SINGER, Jane B. The Journalist in the Network. A Shifting Rationale for the Gatekeeping Role and the Objectivity Norm, Trípodos, $n^{\circ} 23$, Barcelona, 2008, pp. 61-76.

THURMAN, Neil; HERMIDA, Alfred. Gotcha: How newsroom norms are shaping participatory journalism online. In TUNNEY, Sean; GARRETT, Monaghan (Eds.). Web journalism: A new form of citizenship?, Eastbourne: Sussex Academic Press, 2010, pp. 46-62.

VARELA, Juan. Blogs vs. MSM. Periodismo 3.0, la socialización de la información, Revista Telos, $\mathrm{n}^{\circ}$ 65, 2005.

ZAMITH, Fernando. Ferramentas de participação nos ciberjornais de Portugal, in GARCÍA DE TORRES, Elvira (Coord.), Cartografía del Periodismo Participativo. Valencia: Tirant Humanidades, 2012, pp. 305-332.

Este artigo e todo o conteúdo da Estudos em Jornalismo e Mídia estão disponíveis em http://www.periodicos.ufsc.br/index.php/jornalismo/index

Estudos em Jornalismo e Mídia está sob a Licença Creative Commons 